\title{
Zn-limited diet modifies the expression of the rate-regulatory enzymes involved in phosphatidylcholine and cholesterol synthesis
}

\author{
Nidia Noemí Gomez ${ }^{1}$, Verónica Silvina Biaggio ${ }^{1}$, Esteban Javier Rozzen ${ }^{1}$, \\ Silvina Mónica Alvarez ${ }^{1}$ and María Sofía Gimenez ${ }^{2}$ \\ ${ }^{1}$ Departamento de Bioquímica y Ciencias Biológicas, Facultad de Química, Bioquímica y Farmacia, \\ Universidad Nacional de San Luis, San Luis, Argentina \\ ${ }^{2}$ Miembro del Consejo Nacional de Investigaciones Científicas y Técnicas (CONICET), Argentina
}

(Received 9 February 2006 - Revised 10 July 2006 - Accepted 31 July 2006)

\begin{abstract}
Suboptimal intake of $\mathrm{Zn}$ is one of the most common nutritional worldwide problems. Previously, we showed that $\mathrm{Zn}$ deficiency produces alterations in lung lipid metabolism in rats. We studied the effect of a Zn-limited (ZL) diet on the expression of the enzymes involved in phosphatidylcholine and cholesterol synthesis. After 2 months of treatment with a ZL diet we found important variations in the lipid content of Wistar male rats: triacylglycerol (TG) decreased $60 \%(P<0.001)$ while esterified cholesterol (EC), free cholesterol and phospholipids (PL) increased $66 \%, 24 \%$ and $25 \%$ respectively. We also observed a decrease of $40 \%$ in the amount of ${ }^{3} \mathrm{H}$ incorporated into TG and an increase of $47 \%$ and $28 \%$ in the ${ }^{3} \mathrm{H}$ incorporated to PL and EC respectively. Fatty acid synthase and glucose-6-phosphate dehydrogenase activity was increased $(P<0 \cdot 01$ and $P<0 \cdot 05$ respectively). Glycerol-3-phosphate acyltransferase, lipoprotein lipase, diacyl glycerol acyl transferase and 3-hydroxy-3-methylglutaryl CoA reductase expression decreased $(P<0.01$ in all cases), while acetyl CoA carboxylase and cholinephosphate cytidylyltransferase increased $(P<0.01$ and $P<0.005$ respectively). These results suggest that $\mathrm{ZL}$ alters the expression of enzymes involved in phosphatidylcholine and cholesterol synthesis, which could lead to increased PL and cholesterol and decreased TG. This study suggests that major changes in the lipid composition of lung are induced by a ZL condition. Therefore, Zn deficiency must be taken into account in order to design therapies and public health interventions, such as Zn supplementation for high-risk subjects or certain diseases, such as asthma.
\end{abstract}

Lung: Zn-limited diet: Cholesterol: Phospholipid: 3-Hydroxy-3-methylglutaryl CoA reductase: Fatty acid synthase: Cholinephosphate cytidylyltransferase: Lipoprotein lipase

$\mathrm{Zn}$ is an essential nutrient required in man and animals for many physiological functions. Suboptimal intake of dietary $\mathrm{Zn}$ is one of the most common nutritional problems worldwide and it has been shown to exist in low-income groups, institutionalized patients, pregnant women and teenagers, as well as in elderly Americans (Walsh et al. 1994). Zn has been shown to be vital as an antioxidant, microtubule stabilizer, antiapoptotic agent, growth cofactor and anti-inflammatory agent in a variety of tissues (Truong-Tran et al. 2001). Zn may therefore have important implications for asthma and other inflammatory diseases where the physical barrier is vulnerable and compromised (Truong-Tran et al. 2001).

It has also been shown that $\mathrm{Zn}$ deficiency produces profound alterations in the metabolism of lipids (Cunnane \& Yang, 1995; Eder \& Kirchgessner, 1995; DiSilvestro \& Blostein-Fujii, 1997; Kettker et al. 2000). Nevertheless, reports on the effects of $\mathrm{Zn}$ deficiency on lung lipid metabolism are relatively few.

The major phospholipid component (at the air-liquid interface) is phosphatidylcholine (PC) $(70-80 \%)$ and de novo PC synthesis from adult lung rats proceeds mainly via the cytidine diphosphocholine (CDP) pathway (Zimmermann et al. 1993).
Dipalmitoylphosphatidylcholine may be synthesized directly via this pathway or by the remodelling of unsaturated PC species (Zimmermann et al. 1993). The enzyme CTP:phosphocholine cytidylyltransferase (CT) catalyses a rate-regulatory step in the conversion of choline into PC via the Kennedy pathway (Zimmermann et al. 1993). A previous work showed that a moderate Zn deficiency (in vivo) can induce a physiological stimulus that enhances phospholipid synthesis and changes especially the pattern of phospholipids in adult rat lung (Gomez et al. 2002).

Cholesterol appears to be an integral component of pulmonary surfactant and is second only to dipalmitoylphosphatidylcholine as its major component. Cholesterol enhances the stability of surfactant and controls the fluidity of the gas/liquid monomolecular layer (Hayball \& Nicholas, 1989). It may also influence the rate of synthesis of lung phospholipids. Previously, our group found that the increment of cholesterol in serum could be a cause of the increased cholesterol concentration observed in whole lung and macrophages in $\mathrm{Zn}$-deficient animals when compared with the control group (Gomez et al. 2002). On the other hand, it is known that changes in the level of phospholipids would compromise the integrity and function of cell membranes,

\footnotetext{
Abbreviations: CT, CTP:phosphocholine cytidylyltransferase; FAS, fatty acid synthase; G6PDH, glucose-6-phosphate dehydrogenase; HMGCoAR, 3-hydroxy-3methylglutaryl CoA reductase; PC, phosphatidylcholine; SREBP, sterol regulatory element binding protein; TG, triacylglycerol; ZL, Zn-limiting.

* Corresponding author: Dr María Sofía Gimenez, fax +54 2652 431301, email mgimenez@unsl.edu.ar
} 
because these mainly depend on the lipid balance, specifically on the cholesterol:phospholipids ratio (Finney et al. 2000).

In association with these changes, the histopathological study of the lung after $\mathrm{Zn}$ deficiency revealed structural damage in lung parenchyma (Gomez et al. 2002).

In the present study, we examine the effect of moderate $\mathrm{Zn}$ deficiency on the expression of the rate-regulatory enzymes involved in PC and cholesterol synthesis as the main lipid of lung parenchyma in adult rats.

\section{Materials and methods}

\section{Reagents}

$\left[{ }^{3} \mathrm{H}\right] \mathrm{H}_{2} \mathrm{O} \quad(3.70 \mathrm{GBq} / \mathrm{g})$ was purchased from New England Nuclear Life Science Products, Inc. (Boston, MA, USA). Lipid standards were acquired from Sigma Chemical Co. (St. Louis, MO, USA). All the other chemicals were of reagent grade and were obtained from Merck Laboratory (Buenos Aires, Argentina) or from Sigma Chemical Co. Molecular Biology reagents were purchased from Invitrogen (Invitrogen Argentina S.A.) and Promega Inc. (Bio Sciences, USA)

\section{Diet and experimental design}

Wistar male rats $(200 \pm 10 \mathrm{~g})$ were fed two diets with different $\mathrm{Zn}$ concentrations. For that purpose, the rats were separated into two groups and fed a Zn-limiting (ZL) diet containing $7 \mathrm{mg} \mathrm{Zn/kg} \mathrm{and}$ a Zn-adequate control diet supplemented with $30 \mathrm{mg} \mathrm{Zn/kg}$ (added as $\mathrm{ZnCl}_{2}$ ). All the other components of the diet remained constant and were fortified with recommended amounts of vitamins and minerals, according to AIN 93-M diet (Reeves et al. 1993). Both diets had the following composition $(\mathrm{g} / \mathrm{kg})$ : maize starch 466; casein 140 ( $\geq 85 \%$ protein); dextrinized maize starch 155; sucrose 100; fibre/cellulose 50; soyabean oil 40 (containing liposoluble vitamins); mineral mix AIN-93M-MX 35 (Zn was not incorporated into the mineral mix of the ZL diet); vitamin mix 10 (AIN-93-VX); L-cystine 1.8; ascorbic acid 0.008; choline bitartrato 2.5 (41\% choline). All dietary ingredients were monitored for $\mathrm{Zn}$ concentration using atomic absorption spectrophotometry. Animals were housed individually in a controlled environment with $12 \mathrm{~h}$ light $-12 \mathrm{~h}$ dark cycle at $21^{\circ} \mathrm{C}$. Fresh diets were given and left-over food discarded on a daily basis ( $20 \mathrm{~g}$ diet was enough to ensure ad libitum feeding). Animal treatment protocols were previously approved by the local ethics committee and are in accordance with care and treatment of rats recommended guidelines (US Public Health Service, 1985).

Diet acclimatization lasted for 1 week. During that time, the control diet was provided to all rats and intake was measured. Rats with similar intake profiles during the pre-test were matched and assigned to the control or ZL groups. During the experience, body weights were registered weekly.

\section{Serum and tissue collection}

At the end of the experimental period, after 2 months, $12 \mathrm{~h}$ after the last feeding, the animals were killed. Rats were anaesthetized intraperitoneally with sodium pentobarbital $(50 \mathrm{mg} / \mathrm{kg})$. The respiration of the rat was normal at all times prior to killing (respiratory rate was recorded). Blood for determination of $\mathrm{Zn}$ in serum was collected into tubes, washed and rinsed with nitric acid. The lungs were quickly removed, washed with ice-cold
$0.9 \%$ saline solution and weighed. Serum and pieces of lobes of each lung were frozen at $-80^{\circ} \mathrm{C}$ until they were analysed.

\section{Zn analyses}

Aliquots of the diet and lung were collected without allowing any contact with metal. Each sample was wet-ashed with $16 \mathrm{~N}$ nitric acid as described by Clegg et al. (1981). Zn concentrations of the pre-treated samples and serum were quantified by an atomic absorption spectrophotometer (model 5100, HGA-600 Graphite Furnace; Perkin-Elmer, Argentina S.R.L.). A linear calibration curve using certified standard solutions was carried out. All specimens were diluted by bidistilled, deionized water and analysed in duplicate. Before sample digestion, different amounts of standard solution of each element were added. Recovery was between 98 and $99.2 \%$ for different elements.

\section{Serum lipid determinations}

The circulating lipids play a role in the regulation of lipid lung metabolism. We measured serum total cholesterol, HDLcholesterol and triacylglycerol (TG) by colorimetric or enzymatic methods (kits from Wiener, Buenos Aires, Argentina), using fresh serum. All the determinations were performed within $4 \mathrm{~h}$ of obtaining the samples. HDL-cholesterol was measured in the supernatant after precipitation of other lipoproteins by the phosphotungstic- $\mathrm{MgCl}_{2}$ method. LDL- + VLDL-cholesterol was calculated by subtracting the HDL values from total cholesterol values.

\section{Tissue preparation and enzymatic assays}

Lung portions ( $1 \mathrm{~g}$ for $4 \mathrm{ml}$ buffer) were homogenized in an Ultra Turrax T25 homogenizer (Rose Sci. Ltd) in 0.5 M-potassium phosphate buffer ( $\mathrm{pH} 7$ ) containing $10 \mathrm{~mm}-$ EDTA and $10 \mathrm{~mm}-$ D,L-dithiotreitol and protease inhibitors. The homogenates were centrifuged at $100000 \mathrm{~g}$ for $1 \mathrm{~h}$ to yield the cytosolic fraction in a Beckman model L8-80M ultracentrifuge (Beckman Coulter Instruments Inc., USA) with a Ty-80 rotor.

Cytosolic fatty acid synthase (FAS) activity was determined spectrophotometrically by a modified version of the method of Alberts et al. (1974). The reaction mixture contained: $0.5 \mathrm{M}-$ potassium phosphate buffer (pH 6.6); EDTA and dithiotreitol ( $1 \mu \mathrm{mol}$ each); $100 \mathrm{nmol} \mathrm{NADPH}$; the cytosolic fraction $(0.05 \mathrm{ml})$. Adding $100 \mathrm{nmol}$ malonyl-CoA started the reaction and the final assay volume was $1.05 \mathrm{ml}$. The oxidation of $\mathrm{NADPH}$ at $30^{\circ} \mathrm{C}$ was monitored at $340 \mathrm{~nm}$. FAS activity was expressed as units/mg cytosolic proteins.

To measure glucose-6-phosphate dehydrogenase (G6PDH), NADP-isocitrate dehydrogenase and NADP-malic dehydrogenase activity, lungs were homogenized with Tris- $\mathrm{HCl}$ buffer, $\mathrm{pH} 7.4$, containing $1 \mathrm{~mm}$-dithiotreitol. The homogenates were centrifuged at $100000 \mathrm{~g}$ for $1 \mathrm{~h}$ and the enzymatic activities were measured in the supernatant. G6PDH, isocitrate dehydrogenase and malic dehydrogenase were determined by the rate of NADPH formation at $340 \mathrm{~nm}$ according to Glock \& McLean (1953), Farrell (1980) and Bukato et al. (1995).

\section{Lipid determinations}

Lipids were extracted from lung tissue and total lipids were determined by dry weight. The lipids were resuspended in 
hexane-isopropanol mixture $(3: 2, \mathrm{v} / \mathrm{v})$, containing butylated hydroxytoluene as antioxidant (Hara \& Radin, 1978). Aliquots were taken in order to determine phospholipids and to measure P (Rouser et al. 1970) and total cholesterol (Abell et al. 1952). Another part of the extracts was used for the separation of the different lipids on TLC plates coated with silica gel G (Merck, Darmstadt, Germany) using hexane-diethyl ether-acetic acid (80:20:1, by vol.) as solvent. The lipids were detected by exposing the plates to I vapours. They were scraped off and used directly for the determination of phospholipids (Rouser et al. 1970), TG (Sardesai \& Manning, 1968), free and esterified cholesterol (Abell et al. 1952).

\section{Incorporation of $\left[{ }^{3} \mathrm{H}\right]$ from ${ }^{3} \mathrm{H}_{2} \mathrm{O}$ into lung lipids}

All animals were fed ad libitum and then injected intraperitoneally with $37 \mathrm{mBq} \mathrm{mCi} / \mathrm{rat}\left[{ }^{3} \mathrm{H}\right] \mathrm{H}_{2} \mathrm{O}$ in $1 \mathrm{ml}$ saline solution. They were killed $2 \mathrm{~h}$ later to ensure that newly synthesized lipids in the lung had been labelled and $0.250 \mathrm{~g}$ lung was extracted with hexane-isopropanol mixture $(3: 2, \mathrm{v} / \mathrm{v})$ containing butylated hydroxytoluene as antioxidant (Hara \& Radin, 1978). The different lipid fractions were separated by TLC by duplicate (see previous paragraph). They were scraped off and used for determining the incorporated radioactivity in a Beckman LS 100c liquid scintillation counter and the other sample was used for determining the different lipids (Gomez et al. 1999). The results are expressed as ng ${ }^{3} \mathrm{H}$ incorporated/h per $\mathrm{g}$ tissue.

\section{RNA isolation and RT-PCR analysis}

Using TRIzol (Life Technologies Inc., USA), we isolated total RNA. Gel electrophoresis and ethidium bromide staining confirmed the purity and integrity of the samples. Quantification of RNA was based on spectrophotometric analysis at 260/280 nm.

Total RNA $(10 \mu \mathrm{g})$ was reverse-transcribed using MMLV Reverse Transcriptase (Promega Inc.) and random hexamers as primers. RT-generated fragments coding for $\beta$-actin, acetyl CoA carboxylase, glycerol-3-phosphate acyltransferase, diacylglycerol acyltransferase (Waterman et al. 2002), lipoprotein lipase (Zhou et al. 1999), sterol regulatory element binding protein (SREBP)-2 and 1c and CT (Carter et al. 2003) were amplified using PCR.

PCR was performed in reaction solution $(35 \mu \mathrm{l})$ containing

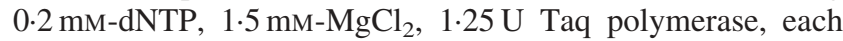
rat specific oligonucleotide primer $(50 \mathrm{pmol})$ and $\mathrm{RT}$ products
(1/10 of RT reaction). The sequences of the different primers as well as the size of the expected PCR products are shown in Table 1. Samples were heated to $94^{\circ} \mathrm{C}$ for $2 \mathrm{~min}$, followed by thirty-eight temperature cycles. Each cycle consisted of three periods: (1) denaturation, $94^{\circ} \mathrm{C}$ for $1 \mathrm{~min}$; (2) annealing, $55^{\circ} \mathrm{C}$ for lipoprotein lipase, acetyl $\mathrm{CoA}$ carboxylase, diacylglycerol acyltransferase, glycerol-3-phosphate acyltransferase, SREBP-2 and $1 \mathrm{c}$ and $\beta$-actin and $60^{\circ} \mathrm{C}$ for CT for $1 \mathrm{~min}$; (3) extension, $72^{\circ} \mathrm{C}$ for $1 \mathrm{~min}$. After thirty-eight reaction cycles, the extension reaction was continued for another $5 \mathrm{~min}$.

The PCR products were electrophoresed on $2 \%$ agarose gel with $0.01 \%$ ethidium bromide. The image was visualized and photographed under UV transillumination and the bands were quantified using NIH Image software (Tucows Inc., USA) and reported as the values of band intensity units. The relative abundance of each band was then normalized according to the housekeeping gene $\beta$-actin, calculated as the ratio of the intensity values of each product to that of $\beta$-actin.

\section{Statistics}

Statistical analysis was performed using Student's $t$ test when only two groups were compared (Snedecor \& Cochran, 1967). When variances were not homogeneous, we performed log transformation of the data. Differences between means were considered significant at the $P<0.05$ level.

\section{Results}

\section{Weight gain and $\mathrm{Zn}$ status of the rats}

Rats fed low Zn were ZL based on body weight and serum Zn concentration (DiSilvestro \& Blostein-Fujii, 1997). Lung weight was significantly lower in ZL after 2 months of treatment (Table 2). There was no change in daily food intake. In our experimental model, clinical signs such as dermatitis or alopecia were not observed.

\section{Total lipids, cholesterol and triacylglycerol in serum}

Given the fact that circulating lipids play a role in the regulation of lung lipid metabolism, we measured the concentrations of several lipids and proteins in the serum of control and ZL rats after 2 months of treatment (Table 3). The increase in (LDL + VLDL) cholesterol fraction in the ZL group was responsible

Table 1. Sequences of the primers used to amplify different genes by RT-PCR*

\begin{tabular}{llll}
\hline CDNA & \multicolumn{1}{c}{ Forward $\left(5^{\prime}-3^{\prime}\right)$} & \multicolumn{1}{c}{ Reverse $\left(5^{\prime}-3^{\prime}\right)$} & Size \\
\hline ACC & ACTCCAGGACAGCACAGATC & TCTGCCAGTCCAATTCTAGC & 535 \\
GPAT & TGATCAGCCAGGAGCAGCTG & AGACAGTATGTGGCACTCTC & 508 \\
LPL & CCTGAAGACTCGCTCTCAGA & TTGGTTTGTCCAGTGTCAGC & 464 \\
DGAT & TTTCTGCTACGGCGGGTTCTTGAG & ACCGGTTGCCCAATGATGAGTGTC & 329 \\
HMGCoAR & GTGATTACCCTGAGCTTAGC & TGGGATGTGCTTAGCATTGA & 462 \\
CT & AGTGGAGGAGAAGAGCATCG & GGAAGTTTGCCAGAGAAGG & 232 \\
SREBP-2 & CACAATATCATTGAAAAGCGCTACC & TTTTTCTGATTGGCCAGCTTCAGCA & 196 \\
SREBP-1C & GGAGCCATGGATTGCACATT & AGGAAGGCTTCCAGAGAGGC & 190 \\
$\beta-A c t i n$ & CGTGGGCCGCCCTAGGCACCA & TTGGCCTTAGGGTTCAGAGGGG & 243 \\
\hline
\end{tabular}

ACC, acetyl CoA carboxylase; GPAT, glycerol-3-phosphate acyltransferase; LPL, lipoprotein lipase; DGAT-1, diacylglycerol acyltransferase 1; HMG-CoAR, 3-hydroxy-3-methylglutaryl CoA reductase; CT, CTP:phosphocholine cytidylyltransferase, SREBP, sterol regulatory element binding protein.

${ }^{*}$ For details of procedures, see p. 1040. 
Table 2. Effects of Zn-limited (ZL) diet on body weight and $\mathrm{Zn}$ concentrations in serum and lung after 2 months of treatment†

(Values are means with their standard errors for ten rats per group)

\begin{tabular}{|c|c|c|c|c|}
\hline & \multicolumn{2}{|c|}{ Control } & \multicolumn{2}{|c|}{ ZL } \\
\hline & Mean & SE & Mean & SE \\
\hline Body weight (g) & $379 \cdot 1$ & 3.7 & $342 \cdot 9^{* *}$ & $3 \cdot 1$ \\
\hline Lung weight $(\mathrm{g})$ & 2.4 & 0.2 & $1 \cdot 9^{\star}$ & $0 \cdot 1$ \\
\hline Daily food intake (g) & $13 \cdot 1$ & 0.3 & $12 \cdot 6$ & 0.5 \\
\hline \multicolumn{5}{|l|}{ Zn concentration } \\
\hline Serum $(\mu \mathrm{mol} / \mathrm{l})$ & $23 \cdot 2$ & $2 \cdot 0$ & $17 \cdot 3^{\star \star}$ & 1.0 \\
\hline Lung ( $\mu \mathrm{mol} / \mathrm{g}$ wet tissue) & 220 & 25 & $130^{\star \star \star}$ & 10 \\
\hline
\end{tabular}

Mean values were significantly different from those for the control group: ${ }^{*} P<0.05$; ${ }^{\star \star} P<0.01 ;{ }^{* \star *} P<0.001$.

†For details of animals and procedures, see p. 1039

for the increase in total cholesterol. There were no changes in the other measures: proteins, total lipids, triacylglycerol and HDLcholesterol between treatment groups.

\section{Triacylglycerols, phospholipids and cholesterol in whole lung}

As shown in Table 4 the concentration of triacylglycerol decreased while phospholipids, free and esterified cholesterol increased when compared with the control group. Under this condition, the concentration of phospholipids and esterified cholesterol was higher in the ZL group.

\section{Activity of fatty acid synthase and dehydrogenases enzymes in lung}

The activity of the lipogenic enzyme FAS showed variations as well as the activity of G6PDH. The increase of FAS was higher than that of G6PDH. However, no changes were observed in isocitrate dehydrogenase and malic dehydrogenase activities (Table 4).

\section{Incorporation of $\left[{ }^{3} \mathrm{H}\right]$ from ${ }^{3} \mathrm{H}_{2} \mathrm{O}$ into lung lipids}

The incorporation of ${ }^{3} \mathrm{H}$ from ${ }^{3} \mathrm{H}_{2} \mathrm{O}$ into the different lipids (specific activity) was modified by $\mathrm{Zn}$ deficiency. We observed a decrease in the incorporation into TG, whereas there was an increased incorporation into phospholipids and esterified cholesterol (Table 5). There were no changes in the incorporation of ${ }^{3} \mathrm{H}$ into free cholesterol between the treated groups.

Table 3. Effects of Zn-limited (ZL) diet on serum concentrations of proteins and different lipids after 2 months of treatment†

(Values are means with their standard errors for eight rats per group)

\begin{tabular}{|c|c|c|c|c|}
\hline & \multicolumn{2}{|c|}{ Control } & \multicolumn{2}{|c|}{ ZL } \\
\hline & Mean & SE & Mean & SE \\
\hline Total proteins (mg/g) & 8.5 & 0.4 & $7 \cdot 8$ & 0.3 \\
\hline Total lipids (mg/g) & 3.5 & 0.7 & $4 \cdot 1$ & 1.6 \\
\hline Triacylglycerol (mmol/l) & 1.13 & 0.11 & 1.47 & 0.34 \\
\hline Total cholesterol $(\mathrm{mmol} / \mathrm{l})$ & 0.55 & 0.01 & $0.69^{*}$ & 0.12 \\
\hline HDL cholesterol (mmol/l) & 0.36 & 0.15 & 0.40 & 0.09 \\
\hline (LDL + VLDL) cholesterol (mmol/l) & 0.18 & 0.09 & $0.28^{\star}$ & 0.003 \\
\hline
\end{tabular}

Mean values were significantly different from those for the control group: ${ }^{\star} P<0.05$. †For details of animals and procedures, see p. 1039.
Expression of glycerol-3-phosphate acyltransferase, lipoprotein lipase, diacylglycerol acyltransferase and acetyl CoA carboxylase in lung

Fig. 1 shows that the expression of glycerol-3-phosphate acyltransferase, lipoprotein lipase and diacylglycerol acyltransferase mRNA was decreased in the ZL group and in concordance with the enzymatic activity of FAS, the expression of acetyl CoA carboxylase mRNA was increased in the $\mathrm{ZL}$ rats.

Expression of 3-hydroxy-3methylglutaryl CoA reductase and sterol regulatory element binding protein-2

We evaluated the expression of 3-hydroxy-3-methylglutaryl CoA reductase (HMGCoAR), the rate-limiting enzyme of cholesterol synthesis. Fig. 2 shows that HMGCoAR decreased its expression. Fig. 3 shows that there were no changes in the SREBP expression between treated groups.

\section{Expression of CTP:phosphocholine cytidylyltransferase}

We then tried to determine if the observed increase of phospholipids was due to an increment of the content of PC by studying the expression of $\mathrm{CT}$, the main regulator of that biosynthetic pathway (Fig. 4), which was effectively increased.

\section{Discussion}

It is known that $\mathrm{Zn}$ deficiency influences the lipid metabolism in a variety of ways (Eder \& Kirchgessner, 1995; Shiratori et al. 1995; Kettker et al. 2000). However, little is known about changes in lung lipid metabolism, specifically in phospholipid content, due to $\mathrm{Zn}$ deficiency. A study from our laboratory showed that lipid concentration in the lung (mainly phospholipids) and the content of PC are modified by a moderate $\mathrm{Zn}$ deficiency (Gomez et al. 2002). For this reason, the aim of the present study was to elucidate which of the lung enzymes involved in lipid metabolism are affected by a ZL diet. For this purpose, a rat model that allows the induction of a ZL diet was used (Shiratori et al. 1995; Gomez et al. 2003; Pfaffl et al. 2003). This model has the advantage that it can be used for a long time and it is physiologically more relevant (Cunnane \& Yang, 1995; Shiratori et al. 1995; Gomez et al. 2003, 2006; Pfaffl et al. 2003). This model is more relevant because severe Zn deficiency can impair many physiological processes, including protein synthesis and feed intake. Also, marginal intake of $\mathrm{Zn}$ is common in industrialized and developing countries. Consequently, marginal $\mathrm{Zn}$ deficiency is believed to be more prevalent than once thought (Christian \& West, 1998).

In our experimental design, the decreased body weight observed in ZL rats confirmed previous results (Cunnane \& Yang, 1995; Shiratori et al. 1995; DiSilvestro \& BlosteinFujii, 1997). The degree of $\mathrm{Zn}$ deficiency was evidenced by the reduction of $\mathrm{Zn}$ concentrations in lung and serum (Shiratori et al. 1995; DiSilvestro \& Blostein-Fujii, 1997). The animals exposed to a ZL diet showed an increase in the levels of total cholesterol and VLDL + LDL; this situation leads to increased vulnerability to oxidative injury (DiSilvestro \& Blostein-Fujii, 1997). In accordance with this situation, our laboratory found that moderate $\mathrm{Zn}$ deficiency in rats could be associated with nitrosative and oxidative stress in lung (Gomez et al. 2006). 
Table 4. Influence of Zn-limited (ZL) diet on triacylglycerol, free and esterified cholesterol, phospholipid concentrations and activities of fatty acid synthase (FAS) and dehydrogenases in lung after 2 months of treatment†

(Values are means with their standard errors for eight rats per group)

\begin{tabular}{|c|c|c|c|c|}
\hline & \multicolumn{2}{|c|}{ Control } & \multicolumn{2}{|c|}{ ZL } \\
\hline & Mean & SE & Mean & SE \\
\hline Triacylglycerol¥ ( $\mu \mathrm{g} / \mathrm{mg}$ protein) & 190 & $13 \cdot 6$ & $87^{\star \star \star}$ & 1.8 \\
\hline Esterified cholesterol§ ( $\mu \mathrm{g} / \mathrm{g}$ tissue) & 399 & 32 & $899^{* \star *}$ & 22 \\
\hline Free cholesterol§ ( $\mu \mathrm{g} / \mathrm{g}$ tissue) & 1750 & 430 & $2295^{\star}$ & 403 \\
\hline Total phospholipids\| (mg/g tissue) & $26 \cdot 1$ & $0 \cdot 10$ & $34 \cdot 4^{\star \star}$ & 1.1 \\
\hline FAS" (nmol NADPH/min per mg protein) & $9 \cdot 1$ & 0.3 & $14 \cdot 2^{\star \star}$ & $1 \cdot 1$ \\
\hline IDH†† ( $\mu \mathrm{mol}$ NADPH/min per mg protein) & $10 \cdot 3$ & 0.8 & 9.9 & 0.5 \\
\hline 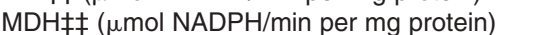 & 13.5 & $2 \cdot 0$ & $12 \cdot 1$ & $3 \cdot 2$ \\
\hline G6PDH§§ ( $\mu \mathrm{mol}$ NADPH/min per mg protein) & $7 \cdot 3$ & 0.4 & $9 \cdot 8^{\star}$ & 0.3 \\
\hline
\end{tabular}

Mean values were significantly different from those for the control group: ${ }^{\star} P<0.05 ;{ }^{\star \star} P<0.01 ;{ }^{* \star \star} P<0.001$.

†For details of animals and procedures, see p. 1039.

¥Determined using the method of Sardesai \& Manning (1968).

$\S$ Determined using the method of Abell et al. (1952).

|l Determined using the method of Rouser et al. (1970).

I Determined using the method of Alberts et al. (1974).

$\dagger \dagger$ Isocitrate dehydrogenase (IDH) determined using the method of Farrell (1980).

$\ddagger \ddagger$ Malic dehydrogenase (MDH) determined using the method of Bukato et al. (1995).

$\S \S$ Glucose-6-phosphate dehydrogenase (G6PDH) determined using the method of Glock \& McLean (1953).

Fatty acid synthesis is an important metabolic pathway that is under complex hormonal and nutritional control. In the present study, we found a decrease in lung TG synthesis evidenced by the diminished incorporation of ${ }^{3} \mathrm{H}\left[\mathrm{H}_{2} \mathrm{O}\right]$. We also studied the activity of FAS and we found it increased by $36 \%$ when compared with control; the expression of acetyl CoA carboxylase also showed a significant increase (Fig. 1). These observations suggest that the amount of fatty acid production may be increased. Those results were also supported by the changed activity of a dehydrogenase enzyme (G6PDH) that provides NADPH for the activity of FAS among other uses such as the regeneration of reduced glutathione. Moreover, only G6PDH increased its activity by $23 \%$, while malic dehydrogenase and isocitrate dehydrogenase did not change in the ZL group (Table 4). Perhaps, the level of reactive oxygen species could affect the levels of NADPH, given the fact that Tavazzi et al. (1999) determined that the pyridine coenzymes could be considered target molecules of reactive oxygen species. This situation was confirmed by our group, which provided experimental evidence of the pro-oxidant effects of a moderate $\mathrm{Zn}$ deficiency in adult rat lung (Gomez et al. 2003, 2006).

Table 5. Effects of $\mathrm{Zn}$-limited (ZL) diet on the incorporation of ${ }^{3} \mathrm{H}$ from $\left[{ }^{3} \mathrm{H}\right] \mathrm{H}_{2} \mathrm{O}$ into the lung lipids $\dagger$

(Values are means with their standard errors)

\begin{tabular}{|c|c|c|c|c|}
\hline & \multicolumn{2}{|c|}{ Control } & \multicolumn{2}{|c|}{ ZL } \\
\hline & Mean & SE & Mean & SE \\
\hline Into TG (ng ${ }^{3} \mathrm{H} / \mathrm{h} / \mathrm{g}$ lung) & 1.3 & 0.1 & $0.8^{*}$ & 0.2 \\
\hline Into $\mathrm{FC}$ (ng ${ }^{3} \mathrm{H} / \mathrm{h} / \mathrm{g}$ lung) & 0.9 & 0.1 & 1.2 & 0.2 \\
\hline Into EC (ng ${ }^{3} \mathrm{H} / \mathrm{h} / \mathrm{g}$ lung) & 0.7 & 0.05 & $0.98^{*}$ & 0.07 \\
\hline Into $\mathrm{PL}$ (ng ${ }^{3} \mathrm{H} / \mathrm{h} / \mathrm{g}$ lung) & 1.9 & 0.3 & $3 \cdot 6^{\star \star}$ & 0.7 \\
\hline
\end{tabular}

TG, triacylglycerol; FC, free cholesterol; EC, esterified cholesterol; PL, phospholipid Mean values were significantly different from those of the respective control groups using Student's $t$ test: ${ }^{*} P<0.05 ;{ }^{\star \star} P<0.01$.

$\dagger$ For details of procedures, see p. 1040.
Lipoprotein lipase, an enzyme linked to hydrolysis and uptake of TG from circulation, was determined in order to study specifically the contribution of exogenous fatty acids in ZL lung. ZL produced a decrease in the expression of lipoprotein lipase when compared with the control group. The present results show that there is not an external contribution of fatty acids in this organ through this way. We would suggest that the fatty acids involved in the synthesis of phospholipids and esterified cholesterol in adult rat lung are increased specifically by endogenous synthesis. Thus, physiological control of these synthetic processes is often coordinated at both transcriptional and post-translational levels. It is known that phospholipids and TG are metabolically interconnected by common lipid intermediates, such as diacylglycerol and fatty acids, which are exchanged in a recycling pathway that could be potentially relevant for membrane synthesis and lipid signal transduction (Igal et al. 2001; Bagnato \& Igal, 2003). Moreover, enzymes for both pathways are subjected to common transcriptional regulation. However, little is known about the mechanism of potential coregulation of TG and phospholipid metabolism (Caviglia et al. 2004). Recently, Caviglia et al. provided evidence indicating that TG synthetic enzymes such as mitochondrial glycerol-3phosphate acyltransferase may indirectly regulate phospholipid synthesis by controlling the availability of lipid substrates (mainly fatty acids and diacylglycerol) for phospholipid formation (Caviglia et al. 2004). On the other hand, a change in tissue fatty acid composition depending on $\mathrm{Zn}$ status has been reported for a variety of tissues (Ayala \& Brenner, 1983; Cunnane et al. 1984) with major differences in the concentrations of oleic, linoleic and arachidonic acid (Ayala \& Brenner, 1983; Cunnane et al. 1984; tom Dieck et al. 2004) and in the ratio of saturated fatty acids and MUFA:PUFA (Eder \& Kirchgessner, 1993; tom Dieck et al. 2004). However, changes of activities of $\Delta 5-, \Delta 6-, \Delta 9$-desaturases were not consistently found in Zn-deficient rats (Eder \& Kirchgessner, 1994, 1995). tom Dieck et al. (2004) provide evidence for a change in fatty acid composition of hepatic lipids in $\mathrm{Zn}$-deficient rats. This situation most likely reflects the down regulation of enzymes 

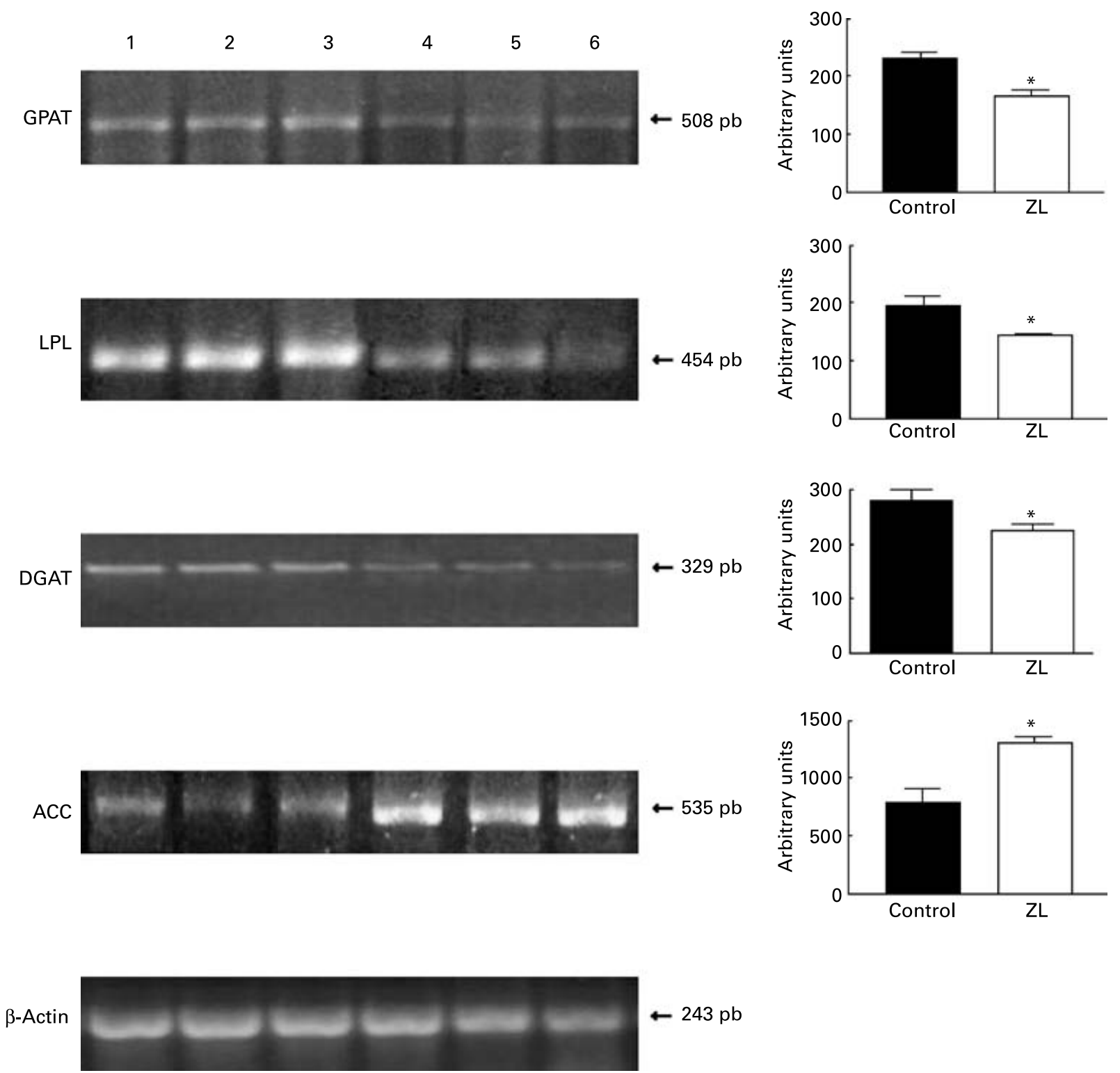

Fig. 1. Expression of enzymes of the triacylglycerol pathway in control and Zn-deficient rats together with the quantification of the intensity of the fragment bands in relation to the intensity of the internal control bands. Ethidium bromide-stained agarose gel of glycerol-3-phosphate acyltransferase (GPAT), lipoprotein lipase (LPL), diacyl glycerol acyltransferase (DGAT), acetyl CoA carboxylase (ACC) and $\beta$-actin PCR products used as an internal control. Lanes 1-3, control samples; lanes $4-6, \mathrm{Zn}$ limited (ZL) samples; pb, pair of bases. Values were significantly different from those of controls; ${ }^{*} P<0.05$. For details of animals and procedures, see p. 1040.

required for fatty acid oxidation in peroxisomes and mitochondria with specificity for SCFA. On the other hand, the palmitate uptake of type II cells increased in parallel with an increase of cholesterol-ester content (Kolleck et al. 2002). Under these conditions, a small but significant increase of palmitate incorporation into phospholipids occurred. For this reason, in this experimental model there might be a redistribution of substrates, where the synthesis of PC is prioritized.

As in our model the amount of 1-acyl-sn-glycerol-3-phosphate decreased, we could suggest that PC would be increased as a consequence of a decreased TG synthesis. We also determined diacylglycerol acyltransferase expression that decreased significantly, which suggests that there would be less synthesis of TG.

Regarding the metabolism of cholesterol, we found an increase in the content of total cholesterol, as a consequence of increased free and esterified cholesterol fractions. However, esterified cholesterol increased more than free cholesterol; this could be due to a higher availability of endogenous fatty acids for cholesterol esterification, perhaps as: (a) a consequence of increased fatty acid synthesis; (b) an increase in cholesterol esterase activity; (c) influx of exogenous fatty acids or a combination of some of those factors. In addition, Hayball \& Nicholas (1989) found that exogenous cholesterol is rapidly esterified in the alveolus. In the present study, higher concentrations of cholesterol fractions are correlated with the incorporation of ${ }^{3} \mathrm{H}$ into esterified cholesterol fractions and a slight increment of ${ }^{3} \mathrm{H}$ incorporated into free cholesterol. To elucidate aspects of this relationship, we measured the expression of HMGCoAR, the rate-limiting enzyme in the pathway, which decreased significantly, perhaps as a consequence of the high level of 

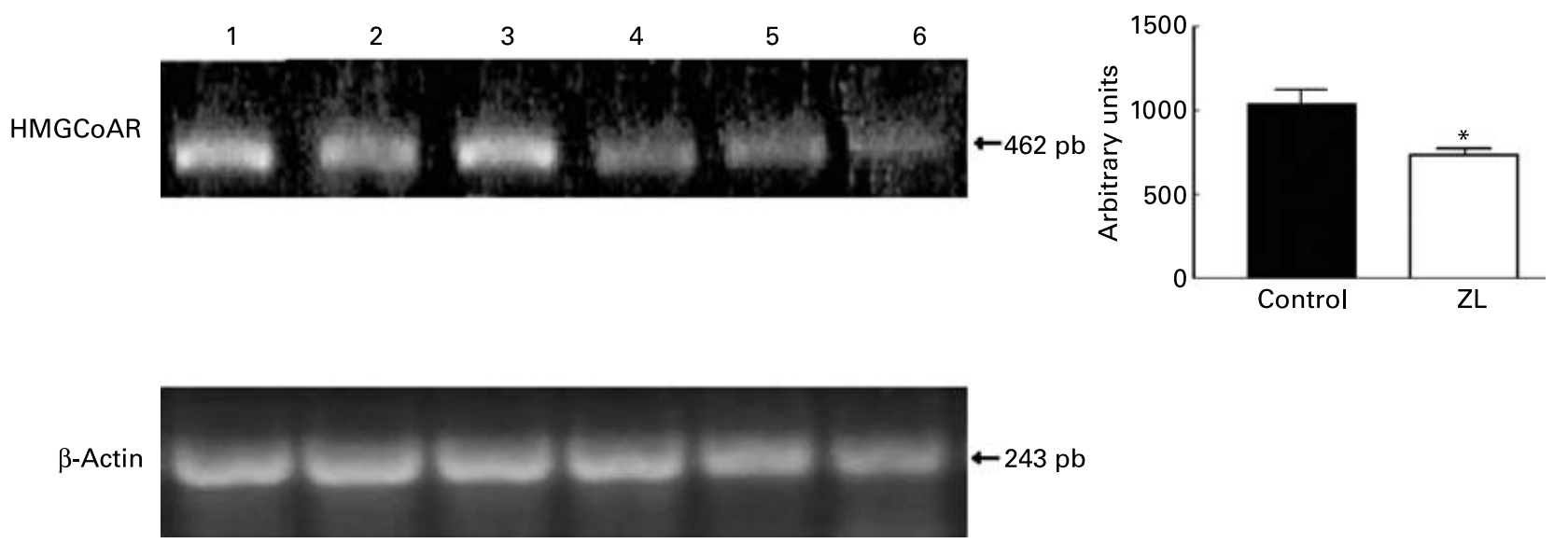

Fig. 2. Expression of genes involved in the cholesterol synthetic pathway together with the quantification of the intensity of the fragment bands in relation to the intensity of the internal control bands. Ethidium bromide-stained agarose gel of 3-hydroxy-3-methylglutaryl CoA reductase (HMGCoAR) and $\beta$-actin PCR products used as an internal control. Lanes 1-3, control samples; lanes 4-6, Zn limited (ZL) samples; pb, pair of bases. Value was significantly different from that of controls; ${ }^{*} P<0.01$. For details of animals and procedures, see $p .1040$.
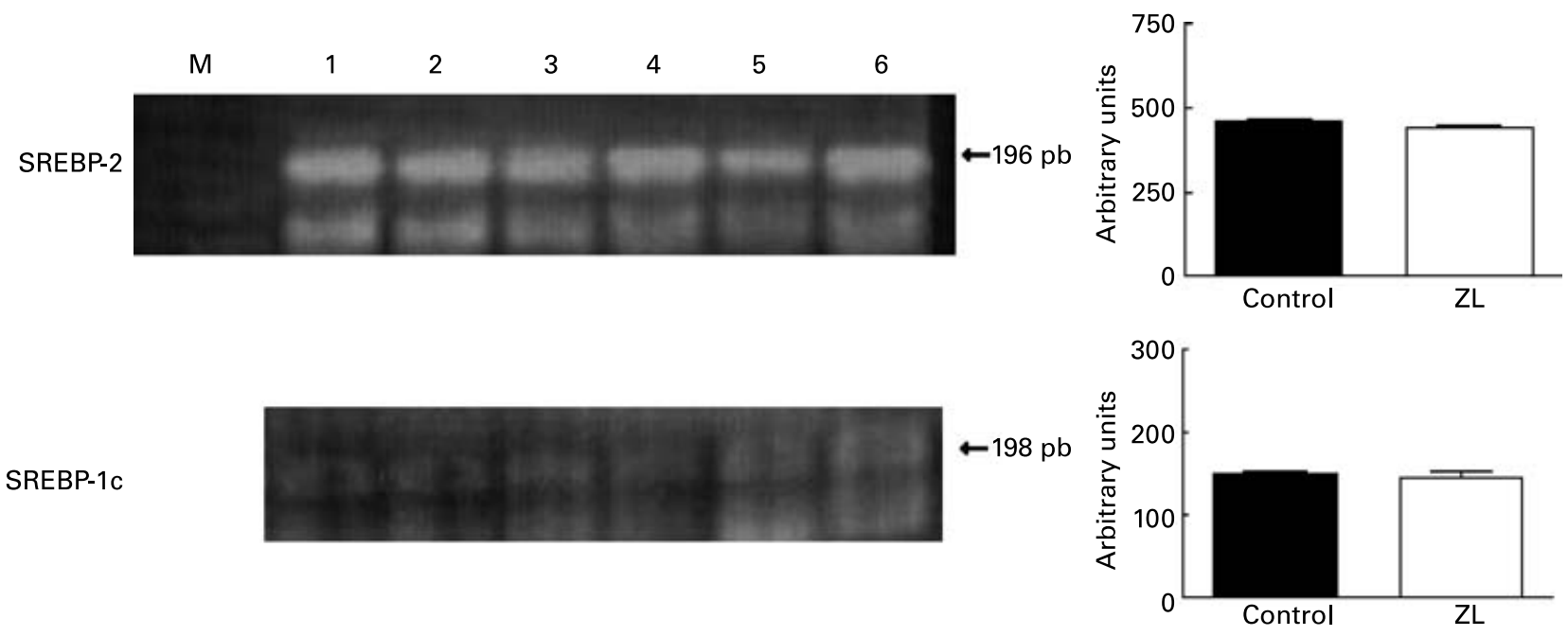

$\beta$-Actin

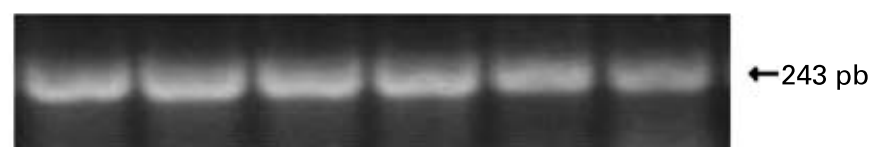

Fig. 3. Expression of sterol regulatory element binding protein (SREBP)-2 and $1 \mathrm{c}$ together with the quantification of the intensity of the fragment bands in relation to the intensity of the internal control bands. Ethidium bromide-stained agarose gel of SREBP-2, SREBP-1c and $\beta$-actin PCR products used as an internal control. M, molecular weight marker; pb, pair of bases; lanes 1-3, control samples; lanes 4-6, Zn limited (ZL) samples. For details of animals and procedures, see p. 1040.

lung cholesterol. The present results are coincident with those presented by Panini et al. (1989). It is known that the expression of HMGCoAR is regulated by SREBP-2. But when we measured the expression of this factor, we did not find significant differences when compared with control. On the other hand, it is known that the activation of SREBP-2 depends on two sequential cleavages. The second cleavage requires the action of a $\mathrm{Zn}$ metalloprotease (Brown \& Goldstein, 1999). In the present experimental conditions, SREBP-2 activation might be diminished due to the absence of $\mathrm{Zn}$. Consequently, we think that the diminution in the expression of HMGCoAR in lung could be due to different factors: as higher influx of cholesterol; less activation of
SREBP-2 by Zn deficiency. This would lead to a decreased expression of HMGCoAR.

Regarding phospholipids, we have found that phospholipid contents were increased in the $\mathrm{Zn}$-deficient model. In the present study, we analysed the incorporation of $\left({ }^{3} \mathrm{H}\left(-\mathrm{H}_{2} \mathrm{O}\right.\right.$ into phospholipids, which was also increased. As PC is the main component of the lung surfactant, and its production was found to be increased (Gomez et al. 2002), we measured the expression of $\mathrm{CT}$ and found that it was also increased. We observed that cholesterol increased in the ZL model, a situation that led to an increased expression and activity of CT (Shiratori et al. 1995; Gomez et al. 2002). 

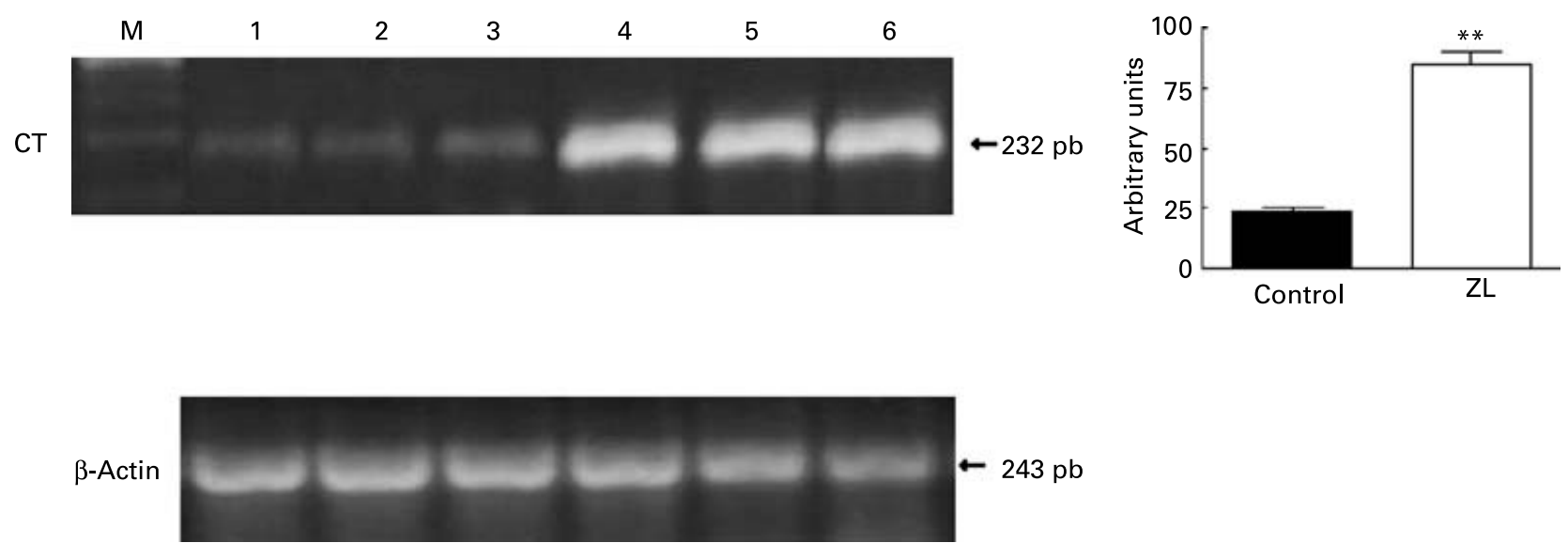

Fig. 4. Expression of CTP:phosphocholine cytidylyltransferase (CT) together with the quantification of the intensity of the fragment bands in relation to the intensity of the internal control bands. Ethidium bromide-stained agarose gel of CT and $\beta$-actin PCR products used as an internal control. M, molecular weight marker; pb, pair of bases; lanes 1-3, control samples; lanes $4-6$, Zn limited (ZL) samples. Value was significantly different from that of controls; ${ }^{\star \star} P<0 \cdot 005$. For details of animals and procedures, see p. 1040 .

Modifications in the major lipid pathways lead specifically to physiological changes. In the present experimental model, the changes observed in lipid pathways reflect a compensatory response to ensure the availability of substrates for phospholipid and cholesterol biosynthetic pathways.

An increasing number of reports are emerging, indicating that changes in PC metabolism are a common feature of the pathophysiology of experimental chronic lung injury or adult respiratory distress syndrome (Vivekananda et al. 2001). Lipid oxidation products have recently been implicated in end-organ damage in human sepsis, including lung injury; these findings suggest important interactions between cytokines, neutrophils, lipids (specifically oxidized forms) and oxygen radicals in the development of acute inflammatory lung injury.

In conclusion, the present results suggest that moderate $\mathrm{Zn}$ deficiency produces alterations in the expression of the enzymes involved in phospholipids, specifically PC, and cholesterol synthesis in lung, which lead to increased phospholipids and cholesterol while TG decreases. This situation is accompanied by an important oxidative and nitrosative stress associated with significant morphological changes in lung parenchyma (Gomez et al. 2003, 2006). In addition, Frey et al. (2000) demonstrated that fragmented phospholipids increase in response to various forms of oxidative stress. On the other hand, fragmented phospholipids were reported in patients with adult respiratory distress syndrome, in which both lung inflammation and hyperoxia are common (Frey et al. 2000). Perhaps, when this situation occurs together with other different pathologies in lungs, it could lead to the worst prognosis in patients at risk.

It would be important to apply the knowledge of $\mathrm{Zn}$ deficiency as a stimulus to understand the complexities of the changes produced in lung lipid metabolism. This situation contributes to a better understanding of the pathophysiology and clinical significance of $\mathrm{Zn}$ deficiency in order to design health interventions in lung.

\section{Acknowledgements}

This research was supported by a grant from CONICET-4931 and National University of San Luis, Project No. 8104.
The authors would like to thank Dr. A. Acosta, Miss I. Sosa and, Mr. R. Dominguez, for their technical assistance.

\section{References}

Abell LL, Levy BB, Brodie BB \& Kendall FE (1952) A simplified method for the estimation of total cholesterol in serum and demonstration of its specificity. J Biol Chem 195, 357-366.

Alberts AW, Ferguson K, Hennessy S \& Vagelos PR (1974) Regulation of lipid synthesis in cultured animal cells. J Biol Chem 249, 5241-5249.

Ayala S \& Brenner RR (1983) Essential fatty acid status in Zn deficiency. Effect on lipid and fatty acid composition, desaturation activity and structure of microsomal membranes of rat liver and testes. Acta Physiol Lat Am 33, 193-204.

Bagnato C \& Igal RA (2003) Overexpression of diacylglycerol acyltransferase-1 reduces phospholipid synthesis, proliferation, and invasiveness in simian virus 40-transformed human lung fibroblasts. J Biol Chem 278, 52203-52211.

Brown MS \& Goldstein JL (1999) A proteolytic pathway that controls the cholesterol content of membranes, cells, and blood. Proc Natl Acad Sci USA 96, 11041-11048.

Bukato G, Kochan Z \& Swierczynski J (1995) Purification and properties of cytosolic and mitochondrial malic enzyme isolated from human brain. Int J Biochem Cell Biol 27, 47-54.

Carter JM, Waite KA, Campenot RB, Vance JE \& Vance DE (2003) Enhanced expression and activation of CTP:phosphocholine cytidylyltransferase beta2 during neurite outgrowth. J Biol Chem 278, 44988-44994.

Caviglia JM, De Gomez Dumm IN, Coleman RA \& Igal RA (2004) Phosphatidylcholine deficiency upregulates enzymes of triacylglycerol metabolism in $\mathrm{CHO}$ cells. J Lipid Res 45, 1500-1509.

Christian P \& West KP Jr (1998) Interactions between Zn and vitamin A: an update. Am J Clin Nutr 68, Suppl. 2, 435S-441S.

Clegg MS, Keen CL, Lonnerdal B \& Hurley LS (1981) Influence of ashing techniques on the analysis of trace elements in animal tissue. 1. Wet ashing. Biol Trace Elem Res 3, 107-115.

Cunnane SC, Horrobin DF \& Manku MS (1984) Essential fatty acids in tissue phospholipids and triglycerides of the $\mathrm{Zn}$-deficient rat. Proc Soc Exp Biol Med 177, 441-446.

Cunnane SC \& Yang J (1995) Zinc deficiency impairs whole-body accumulation of polyunsaturates and increases the utilization of 
[1-14C] linoleate for de novo lipid synthesis in pregnant rats. Can $J$ Physiol Pharmacol 73, 1246-1252.

DiSilvestro RA \& Blostein-Fujii A (1997) Moderate zinc deficiency in rats enhances lipoprotein oxidation in vitro. Free Radic Biol Med 22, 739-742.

Eder K \& Kirchgessner M (1993) The effect of Zn depletion on the fat content and fatty acid composition of the liver and brain in forcibly fed rats. Z Ernahrungswiss 32, 187-197.

Eder K \& Kirchgessner M (1994) Level of polyunsaturated fatty acids in tissues from Zn-deficient rats fed a linseed oil diet. Lipids 29, 839-844.

Eder K \& Kirchgessner M (1995) Zinc deficiency and activities of lipogenic and glycolytic enzymes in liver of rats fed coconut oil or linseed oil. Lipids 30, 63-69.

Farrell HM Jr (1980) Purification and properties of NADP + : isocitrate dehidrogenase from lactating bovine mammary gland. Arch Biochem Biophys 204, 551-559.

Finney RE, Nudelman E, White T, Bursten S, Klein P, Leer LL, Wang N, Waggoner D, Singer JW \& Lewis RA (2000) Pharmacological inhibition of phosphatidylcholine biosynthesis is associated with induction of phosphatidylinositol accumulation and cytolysis of neoplastic cell lines. Cancer Res 60, 5204-5213.

Frey B, Haupt R, Alms S, Holzmann G, Konig T, Kern H, Kox W, Rustow B \& Schlame M (2000) Increase in fragmented phosphatidylcholine in blood plasma by oxidative stress. J Lipid Res $\mathbf{4 1}$, $1145-1153$.

Glock GE \& McLean P (1953) Further studies on the properties and assay of glucose-6-phosphate dehydrogenase and 6-phosphogluconate dehydrogenase of rat liver. Biochem J 55, 400-408.

Gomez NN, Davicino RC, Biaggio VS, Bianco GA, Alvarez SM, Fischer P, Masnatta L, Rabinovich GA \& Gimenez MS (2006) Overexpression of inducible nitric oxide synthase and cyclooxygenase-2 in rat Zn-deficient lung: Involvement of a NF-kappaB dependent pathway. Nitric Oxide 14, 30-38.

Gomez NN, Fernandez MR, Zirulnik F, Ojeda MS \& Gimenez MS (2003) Chronic zinc deficiency induces antioxidant adaptive response in rat lung. Exp Lung Res 29, 485-502.

Gomez NN, Ojeda MS \& Gimenez MS (1999) Incorporation of ${ }^{3} \mathrm{H}_{2} \mathrm{O}$ into lipids of adult male rat lung after castration. J Radioanal Nucl Chem 240, 455-456.

Gomez NN, Ojeda MS \& Gimenez MS (2002) Lung lipid composition in zinc-deficient diet. Lipids 37, 291-296.

Hara A \& Radin NS (1978) Lipid extraction of tissues with a low-toxicity solvent. Anal Biochem 90, 420-426.

Hayball PJ \& Nicholas TE (1989) The processing of exogenous cholesterol in the alveolar compartment of the rat lung. Lipids 24, 957-961.

Igal RA, Caviglia JM, de Gomez Dumm IN \& Coleman RA (2001) Diacylglycerol generated in $\mathrm{CHO}$ cell plasma membrane by phospholipase $\mathrm{C}$ is used for triacylglycerol synthesis. J Lipid Res 42, 88-95.

Kettker SI, Eder K, Kettker A \& Kirchgessner M (2000) Zinc deficiency and the activities of lipoprotein lipase in plasma and tissues of rats force-fed diets with coconut oil or fish oil. $J$ Nutr Biochem 11, 132-138.

Kolleck I, Gutyhmann F, Ladhoff AM, Tandon NN, Schlame M \& Rustow B (2002) Cellular cholesterol stimulates acute uptake of palmitate by redistribution of fatty acid translocase in type II pneumocytes. Biochemistry 41, 6369-6375.

Panini SR, Schnitzer-Polokoff R, Spencer TA \& Sinensky M (1989) Sterol-independent regulation of 3-hydroxy-3-methylglutaryl-CoA reductase by mevalonate in Chinese hamster ovary cells. Magnitude and specificity. J Biol Chem 264, 11044-11052.

Pfaffl MW, Gerstmayer B, Bosio A \& Windisch W (2003) Effect of Zn deficiency on the mRNA expression pattern in liver and jejunum of adult rats: Monitoring gene expression using cDNA microarrays combined with real-time RT-PCR. J Nutr Bioch 14, 691-702.

Reeves PG, Nielsen FH \& Fahey GC (1993) AIN-93 purified diets for laboratory rodents: Final report of the American Institute of Nutrition Ad Hoc Writing Committee on the reformulation of the AIN76A rodent diet. J Nutr 123, 1939-1951.

Rouser G, Fluster S \& Yamamoto A (1970) Two-dimensional thinlayer chromatographic separation of polar lipid and determination of phospholipids analysis of spots. Lipids 5, 494-496.

Sardesai VM \& Manning JA (1968) Determination of triglycerides in plasma and tissues. Clin Chem 14, 156-161.

Shiratori Y, Houweling M, Zha X \& Tabas I (1995) Stimulation of CTP-phosphocholine cytidylyltransferase by free cholesterol loading of macrophages involves signaling through protein dephosphorylation. J Biol Chem 270, 29894-29903.

Snedecor GW \& Cochran WG (1967) Statistical Methods, 6th edition, pp. 342-343. Ames, IA: Iowa State University Press.

Tavazzi B, Di Pierro D, Amorini AM, Fazzina G, Galvano M, Lupi A, Giardina B \& Lazzarino G (1999) Direct NAD(P)H hydrolysis into ADP-ribose $(\mathrm{P})$ and nicotinamide induced by reactive oxygen species: a new mechanism of oxygen radical toxicity. Free Radic Res 33, 1-12.

tom Dieck H, Doring F, Fuchs D, Roth HP \& Daniel H (2004) Transcriptome and proteome analysis identifies the pathways that increase hepatic lipid accumulation in Zn-deficient rats. $J$ Nutr 135, 199-205.

Truong-Tran AQ, Carter J, Ruffin R \& Zalewski PD (2001) New insights into the role of $\mathrm{Zn}$ in the respiratory epithelium. Immunol Cell Biol 79, 170-177.

US Public Health Service (1985) Guide to the Care and Use of Laboratory Animals, pp. 25-83. Bethesda, MD: National Institutes of Health.

Vivekananda J, Smith D \& King RJ (2001) Sphingomyelin metabolites inhibit sphingomyelin synthase and CTP:phosphocholine cytidylyltransferase. Am J Physiol Lung Cell Mol Physiol 281, L98-L107.

Walsh CT, Sandstead HH, Prasad AS, Newberne PM \& Fraker PJ (1994) Zinc: health effects and research priorities for the 1990s. Environ Health Perspect 102, Suppl. 2, 5-46.

Waterman IJ, Price NT \& Zammit VA (2002) Distinct ontogenetic patterns of overt and latent DGAT activities of rat liver microsomes. J Lipid Res 43, 1555-1562.

Zhou YT, Wang ZW, Higa M, Newgard CB \& Unger RH (1999) Reversing adipocyte differentiation: implication for treatment of obesity. Proc Natl Acad Sci USA 96, 2391-2395.

Zimmermann LJ, Hogan M, Carlson KS, Smith BT \& Post M (1993) Regulation of phosphatidylcholine synthesis in fetal type II cells by CTP:phosphocholine cytidylyltransferase. Am J Physiol 264, L575-L580. 